\title{
A NOVA ECONOMIA INSTITUCIONAL E SUA APLICAÇÃO NO ESTUDO DO AGRONEGÓCIO BRASILEIRO ${ }^{1}$
}

\author{
Krisley Mendes ${ }^{2}$ \\ Jeovan de Carvalho Figueiredo ${ }^{3}$ \\ Ido Luiz Michels ${ }^{4}$
}

\begin{abstract}
Resumo: Este trabalho resgata a raiz teórica à qual se vincula a Nova Economia Institucional (NEI). Mostra que a NEI, em debate com outras correntes institucionalistas, revela limitações e contradições teóricas importantes. A falta desse resgate nos estudos sobre agronegócio impede a observação de questões importantes do agronegócio brasileiro, como conflito, cultura e poder na formação das estruturas de governança. O trabalho apresenta, primeiramente, o vínculo entre compreender o agronegócio de forma sistêmica e o pensamento institucionalista. Em seguida, resgata as origens e as correntes da Economia Institucional e mostra que a NEI se vincula ao individualismo metodológico, o que a distancia do institucionalismo original. Conclui-se que a NEI é um arcabouço teórico limitado para a compreensão das estruturas de governança observadas no Brasil, sobretudo no agronegócio brasileiro.
\end{abstract}

Palavras-chave: institucionalismo, nova economia institucional, cadeias produtivas.

\section{Introdução}

A motivação desse recorte partiu da observação intuitiva de que o instrumento teórico predominante nos estudos do agronegócio brasileiro, qual seja, a Nova Economia Institucional (NEI), não fornecia elementos suficientes para explicar formas ineficientes de organização da firma ou da cadeia e que a coordenação de uma cadeia ou sistema agroindustrial

Recebido em 30/10/2009; Aceito em 16/01/2009

Mestre em Agronegócios - UFMS. Professora do Centro de Ensino Superior de Rondonópolis. Rondonópolis, MT.E-mail: krisley.mendes@uol.com.br.

3 Doutor em Administração de Empresas - FGV -EAESP. São Paulo, SP. E-mail: jeovanfigueiredo@ gvmail.br.

4 Doutor em Geografia (Geografia Humana) - USP. Professor Adjunto IV da UFMS, Campo Grande, MS. E-mail: idomichels@uol.com.br. 
não necessariamente promoveria o melhor desempenho sistêmico.Caso fosse verdade, resultaria em teorias políticas inócuas para promoção de competitividade.

Castro (2004) mostrou que a abordagem neoinstitucionalista, aplicada ao estudo do agronegócio, produz uma análise muito particular e até limitada das estratégias empresariais. Goldbaum (1998) observou que a NEI atribui eficiência às estruturas de governança, mas essa eficiência não é demonstrada, apenas deduzida.

A realidade empírica inspiradora veio da cadeia da carne bovina de Mato Grosso do Sul. No ano de 2000, foi iniciado o Programa de Competitividade da Cadeia Produtiva da Carne Bovina de MS, cuja implementação foi motivada por estudo preliminar realizado pelo Grupo $\mathrm{PENSA}^{5}$, principal disseminador da NEI no Brasil. O programa objetivou ser um instrumento de coordenação da cadeia que promovesse o encontro entre os agentes que a compunham, no qual pudessem acordar políticas que solucionassem os problemas. Em que pesem os inúmeros resultados positivos obtidos pelo Programa, a coordenação não vingou, principalmente pela ausência do elo frigorífico. Essa ausência era uma evidência de que o poder de mercado, exercido pelos frigoríficos, fazia-os dispensar formas de coordenação alternativas. Daí resulta a hipótese de que a teoria estaria limitando as possibilidades de compreensão e de superação de nós na cadeia, uma vez que não abordava apropriadamente questões como poder e cultura.

Este trabalho visa compreender as contribuições, as limitações e as contradições teóricas da Nova Economia Institucional e suas implicações no estudo do agronegócio brasileiro na proposição de políticas de competitividade.

\footnotetext{
O Grupo PENSA (Programa de Estudos dos Negócios do Sistema Agroindustrial) foi instalado em 1990 pela USP, com a finalidade de promover estudos sobre o agribusiness brasileiro. Seus trabalhos fundamentam-se na abordagem sistêmica do agronegócio, predominantemente a partir do enfoque dado por Commodity Sistem Aproach (CSA) ou Sistemas Agroindustriais (SAG). Esse enfoque é combinado com os pressupostos teóricos da Nova Economia Institucional.
} 
O estudo caracteriza-se pela investigação teórica, de abordagem hipotéticodedutiva. Transita, portanto, principalmente pelo campo de pesquisa da economia positiva e classifica-se como uma pesquisa explicativa, apoiada, primordialmente, em estudos bibliográficos.

\section{Abordagem sistêmica do agronegócio}

A abordagem de Sistemas Agroindustriais - SAG (ou Commodity System Approach - CSA) foi apresentada por Davis e Goldberg em 1957. Por meio dessa abordagem, o sistema agroindustrial é entendido como um nexo de contratos e apóia-se em uma cadeia produtiva, abrangendo segmentos antes, dentro e depois da porteira (FARINA; ZYLBERSZTAJN, 1996, p.4). Esse enfoque inaugura o estudo do agronegócio baseado em uma visão sistêmica, a montante (de dentro ou anterior à fazenda) e a jusante (para fora da fazenda), e é importante para o apoio à tomada de decisões corporativas (AMARAL et al., 2003, p. 67).

A visão sistêmica é caracterizada pelo nível de agregação dada à atividade produtiva, não mais dividida entre setores agrícola, industrial e de serviços, mas perpassando esses setores. É caracterizada também pela análise de um produto específico e pela inclusão das instituições como uma variável não-neutra (FARINA; ZYLBERSZTAJN, 1996).

A base teórica do SAG deriva da teoria da produção neoclássica com forte influência da matriz de produção de Leontieff, que permitiu a introdução do conceito de interdependência setorial (FARINA, ZYLBERSZTAJN, 1996). Considera os níveis micro, da análise da firma, e macro, introduzindo variáveis macroeconômicas que interferem no sistema, dando especial ênfase ao papel das instituições. 
No estudo encomendado pelo IEL, CNA e SEBRAE ${ }^{6}$, afirma-se que o SAG está mais relacionado com a observação macro do sistema e com as medidas de regulação dos mercados, oferecendo o arcabouço necessário para a compreensão da forma como o sistema funciona e sugerindo as variáveis que afetam seu desempenho (BATALHA; SILVA, 2000, pp 19-21). Nesse mesmo estudo, é lembrado que a abordagem sistêmica do SAG "está fundamentada em estudos originalmente desenvolvidos nas ciências biológicas e engenharias [onde] um sistema é compreendido por dois aspectos: uma coleção de elementos e uma rede de relações funcionais, as quais atuam em conjunto para o alcance de algum propósito determinado" (BATALHA; SILVA, 2000, p. 19 grifo dos autores).

A evolução do conceito de sistema agroindustrial o transporta da matriz insumo-produto, de Leontieff, para a estrutura analítica de Organização Industrial, que põe em pauta a tríade estrutura-conduta-desempenho. A adaptabilidade ao ambiente econômico e a aspectos dinâmicos, como mudanças tecnológicas, passa a compor aspectos da competitividade, não mais individual, mas sistêmica. A estrutura de contratos que permeia as relações entre os agentes e a figura de um (ou vários) agente coordenador são aspectos das inter-relações setoriais. Como conseqüência, destaca-se a importância da estabilidade institucional que garante o cumprimento dos contratos e da legalidade das relações ao desempenho do sistema. Outra característica desse enfoque é que o sistema não se constitui de mera soma das partes. O sistema agroindustrial provém de padrões sistemáticos de interação entre os agentes envolvidos (BATALHA; SILVA, 2000, p. 21).

Outra corrente que segue a abordagem sistêmica para análise do agronegócio introduziu o conceito de filière, ou cadeia, que provém da escola francesa, com forte tradição na análise das relações intersetoriais desde Quesnais. Agregam-se autores marxistas e a Teoria Geral de

Instituto Evaldo Lodi - IEL, Serviço Brasileiro de Apoio às pequenas e micro Empresas - SEBRAE, Confederação da Agricultura e Pecuária do Brasil-CNA. Estudo sobre a eficiência econômica e competitividade da cadeia agroindustrial da pecuária de corte no Brasil. 
Sistemas, preocupados com aspectos distributivos do produto (FARINA; ZYLBERSTAJN, 1994, p. 16).

O que diferencia esse enfoque do anteriormente mencionado é que a filière, ou cadeia, focaliza aspectos de hierarquização e poder de mercado. Para Farina e Zylberstajn (1994), isso faz com que o enfoque de filière seja mais voltado para políticas públicas e com que o de sistema, para estratégias corporativas. No trabalho encomendado pelo IEL, CNA e SEBRAE, os dois conceitos são apontados, indistintamente como mais úteis para a elaboração de políticas setoriais públicas e privadas, e menos eficientes em apontar ferramentas gerenciais de operacionalização de ações conjuntas que aumentem o nível de coordenação da cadeia (BATALHA; SILVA, 2000, p. 22). Esta última é melhor subsidiada pelo enfoque de supply chain management (SCM) (BATALHA; SILVA, 2000). Farina e Zylberstajn (1994) enfatizam que o grau de coordenação e a forma pela qual esta se materializa constituem diferenças importantes entre os enfoques filière e sistema.

O Sistema Agroindustrial específico é entendido como uma composição de firmas com distintos níveis de coordenação vertical. Entre essas firmas são realizadas transações que podem ocorrer no mercado (spot) ou via contratos (formais e informais). As instituições compõem o ambiente no qual essas transações ocorrem. Portanto, interferem tanto na definição dos objetivos das organizações quanto nas estruturas de governança adotadas (FARINA; AZEVEDO; SAES, 1997). Os elementos fundamentais para a descrição dos sistemas agroindustriais são os agentes envolvidos, as relações entre eles, os setores, as organizações de apoio e o ambiente institucional (ZYLBERSTAJN, 2000).

Assim, o agronegócio é estudado em seus diversos ramos como um nexo de contratos, compostos de sucessivas etapas que vão desde o produtor e revendedor de insumos até o consumidor, passando pelo produtor rural, pela indústria e pelo comércio. Dessa forma ampla, o ambiente institucional assume relevância, visto que é capaz de determinar o grau de competitividade e as possibilidades de melhor desempenho, razão pela qual é campo fértil para a aplicação da abordagem institucional. 


\section{Abordagem institucional do agronegócio}

A abordagem institucional é constituída por vários ramos teóricos, dentre eles, a Nova Economia Institucional. O institucionalismo nasceu em fins do século XIX e veio a ser esquecido a partir de 1920 (GUEDES, 2004). Em 1960, a abordagem foi resgatada, diferenciada pelo adjetivo nova. A Nova Economia Institucional, que tem Coase como elo de ligação entre o velho e o novo institucionalismo, tem em Williamson e North as principais expressões. No entanto, as diferenças entre o "velho" e o "novo" institucionalismo são marcantes (GUEDES, 2004).

Características do institucionalismo são encontradas em autores tão díspares quanto Marx e Pareto, mas é nos autores alemães do século XIX que se pode datar essa corrente como escola do pensamento econômico (GUEDES, 2004). Entretanto, foi a influência desses autores alemães sobre estudiosos norte-americanos que fez com que a abordagem institucional ganhasse sustentação e projeção.

O antigo institucionalismo é caracterizado, em oposição à escola clássica liberal e neoclássica, por reivindicar o caráter histórico dos fenômenos econômicos (GUEDES, 2004). Idealista, nacionalista, empiricista e profundamente influenciado pela biologia darwinista, o institucionalismo alemão ganhou nos EUA novas influências. Agregaram-se ao institucionalismo influências da psicologia instintiva de Dewey, que serviu para a crítica da racionalidade neoclássica, e do pragmatismo filosófico, que permitiu uma unidade teórico-metodológica (GUEDES, 2003). O enfoque é interdisciplinar e evolucionista, já que considera que os problemas econômicos sejam dinâmicos e envolvam valores, costumes, tecnologia e instituições (MENDONÇA, 2003).

A centralidade analítica do indivíduo, foco da abordagem clássica liberal, é deslocada para a instituição, como unidade de análise (GUEDES, 2004). A justificativa para esse ponto de partida é que "o fato de as instituições tipicamente registrarem um grau de invariância ao longo de extensos períodos de tempo e poderem sobreviver aos indivíduos oferece as razões 
para escolhê-las, ao invés dos indivíduos, como unidade básica" (HODGSON,1998, p.172). Atendo-se às especificidades institucionais, a escola nega-se a construir "um modelo geral e a-histórico do agente individual" (HODGSON,1998, p.172) e inclui, como relevante, o papel de hábitos, rotinas e instituições na condução do desenvolvimento econômico. "Em termos conceituais, o hábito tem uma estatura explicativa superior ao de escolha racional" (GUEDES, 2004).

Apesar de permanecer influenciando autores contemporâneos, como Galbraith e Polaniy, o "velho" institucionalismo perdeu fôlego a partir de 1920. A Nova Economia Institucional retoma, nos anos de 1960, alguns dos conceitos desenvolvidos pela abordagem institucionalista, mas resgata um vínculo com o maistream.

\subsection{Linhas teóricas e critérios de diferenciação}

A ampla gama de autores presentes na abordagem institucional e a conseqüente diversificação de idéias que dificultam uma coesão teórica (MENDONÇA; 2003) têm desenvolvido uma heterogeneidade de escolas (HALL; TAYLOR, 1996. GUEDES, 2004. THÉRET, 2003), que abrigam diferentes enfoques, às vezes inconciliáveis (CONCEIÇÃO, 2003). Isso é resultado do caráter interdisciplinar dessa abordagem e, sobretudo, da relevância que o papel das instituições passou a ter nos últimos vinte anos (HALL;TAYLOR, 1996; THÉRET, 2003; ZYLBERSTAJN, 1995; SILVA, 2004).

As várias ramificações do pensamento institucionalista, especialmente na Ciência Política, na Economia e na Sociologia, podem ser vistas subdivididas em outras tantas tendências (THÉRET, 2003). O que as aproxima é a crença de que os dispositivos institucionais e os processos sociais são importantes (THÉRET, 2003).

Hall e Taylor (1996) identificaram três correntes na Ciência Política, quais sejam, o institucionalismo histórico, o institucionalismo da escolha 
racional e o institucionalismo sociológico (da teoria das organizações). Théret (2003) apresentou os institucionalistas da Economia em três tendências - teoria da regulação, nova economia institucional e economia das convenções; e o da Sociologia - institucionalismo sociológico, da escolha racional e histórico cultural.

O que diferencia os institucionalismos é a "ênfase que atribuem ao caráter micro ou macro dos fenômenos institucionais, ao peso que imputam nos aspectos cognitivos ou normativos das instituições, e à atenção que dispensam aos interesses e às redes de relações na criação e difusão das instituições" (DIMAGGIO; POWEL, 1997 p. 23).

Outra sugestão de diferenciação entre as correntes aponta duas grandes oposições: "1) O peso que atribuem na gênese das instituições aos conflitos de interesse e de poder ou à coordenação entre indivíduos; 2) O papel que imaginam que desempenham na relação entre as instituições e no comportamento dos atores a racionalidade instrumental calculadora ou as representações e a cultura" (THÉRET, 2003, p. 226). Esses diferentes pesos resultam em explicações diferentes sobre a relação indivíduo/ instituição e sobre a gênese das instituições, bem como em processos de mudança.

A figura abaixo representa os posicionamentos das diferentes correntes institucionalistas, de acordo com o peso que atribuem aos critérios de diferenciação cálculo/cultural, para explicação da relação indivíduo/ instituição, e aos de coordenação/conflito, para explicação da gênese das instituições. 


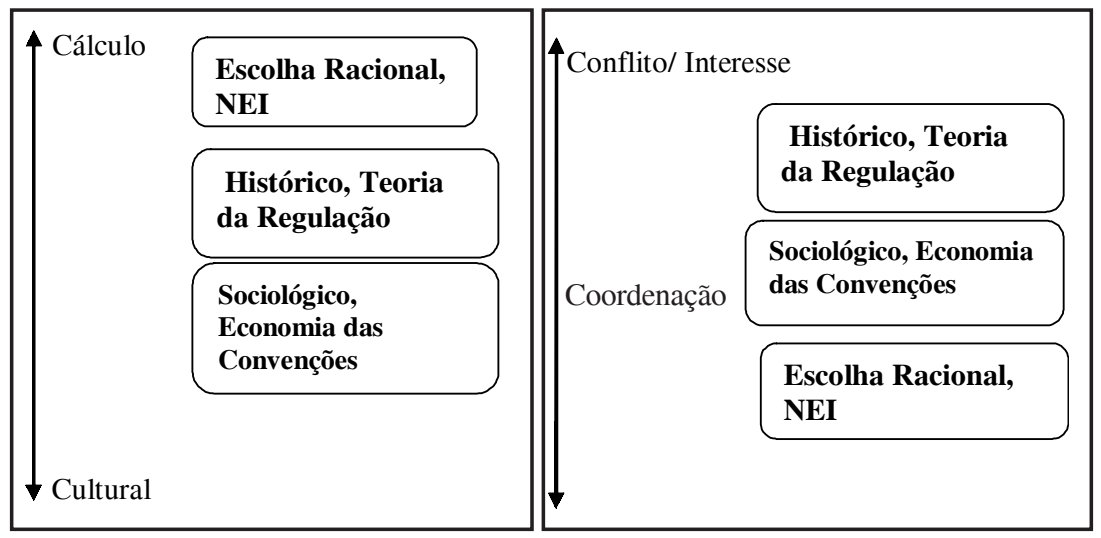

Fonte: adaptado de Théret (2003). Elaborado pelos autores.

Figura 1 - Critérios metodológicos de diferenciação entre os institucionalismos

\subsubsection{Primeiro Critério: Cálculo/ Cultura}

O cálculo representa um caráter instrumental e estratégico do comportamento. Em razão disso, a instituição tem o efeito de reduzir as incertezas, e o resultado da interação indivíduo/estrutura é intencional. No outro pólo, maior peso à cultura requer reconhecer a influência de rotinas e de valores. Dessa forma, as instituições refletem planos morais e cognitivos que referenciam as ações individuais. As instituições, portanto, são convencionais, resistem à mudança e condicionam as ações individuais.

De acordo com o critério cálculo/cultural, a nova economia institucional e o institucionalismo das escolhas racionais, num pólo, atribuem à racionalidade dos indivíduos, a seus cálculos e às suas estratégias a causa de seus relacionamentos institucionais; enquanto no outro pólo está o institucionalismo sociológico e a economia das convenções, que atribuem maior peso a hábitos, rotinas e valores culturais como elementos que conduzem o relacionamento indivíduo/instituição, ao defenderem que os indivíduos são condicionados por valores, e não por cálculos estratégicos. 
O institucionalismo histórico e a teoria da regulação posicionam-se num meio termo, eclético, atribuindo ao cálculo e à cultura pesos equivalentes no condicionamento indivíduo/estrutura. Dessa forma, o indivíduo racionaliza suas atitudes para o alcance de seus interesses, mas leva em conta valores e hábitos. Isso implica reconhecer que, mesmo que guiados racionalmente por seus interesses, os indivíduos constroem esses interesses politicamente.

\subsubsection{Segundo Critério: Conflito/Coordenação}

Já no critério de diferenciação conflito/coordenação, atribuído à gênese das instituições, as correntes situam-se nos extremos. Em um pólo, o institucionalismo histórico cultural, que, ao atribuir ao conflito de interesses e ao poder político os condicionantes que originam as instituições, confere às instituições a função de regular conflitos.

No outro conflito, estão a nova economia institucional, o institucionalismo das escolhas racionais, o sociológico e a economia das convenções. Essas quatro escolas atribuem à coordenação, ou a um processo cooperativo, a razão da constituição de instituições. Esse valor à coordenação é dado a partir de concepções diferentes, de modo que se podem separar essas quatro escolas em duplas, pela afinidade.

Nos dois primeiros (nova economia institucional e institucionalismo das escolhas racionais), o cálculo de interesses resulta em coordenação entre os agentes, que buscam, com isso, reduzir as incertezas no ambiente. Assim, pode-se dizer que, para a nova economia institucional, as instituições são o agregado do cálculo custo/benefício individuais.

Para o institucionalismo sociológico e para a economia das convenções, a origem das instituições está na observação de regras e de convenções. As instituições funcionam como constrangimento à ação individual. Enquanto para a dupla anterior, as instituições funcionam como instrumentos de libertação da ação individual, não como constrangimento 
para a nova economia das instituições, o indivíduo tem maior poder de intervenção nas instituições.

\subsection{Convergências e Divergências}

Théret (2003) demonstrou que há convergência dos três macro-paradigmas (histórico, racional e sociológico). Essa convergência foi iniciada pelo institucionalismo histórico da Ciência Política, que reconhece a postura racional e também cultural das ações individuais, enquanto no critério conflito/coordenação não há aproximações concretizadas.

Não se trata de achar que os pólos vão se encontrar, mas é possível construir mediações. Da mesma forma que cálculo e cultura estão presentes e condicionam as escolhas individuais, como defendido pelo institucionalismo histórico, também podem ser defendidas mediações entre conflito e coordenação que condiciom a origem e as mudanças institucionais. Nesse aspecto, volta-se ao antigo institucionalismo de Commons ${ }^{7}$, que reconhece que as transações ocorrem por interdependência das partes, tornando-as propícias à coordenação, mas é conflituosa pela apropriação do resultado da transação.

Nesta análise, entende-se que as instituições permitiriam estabelecer limites entre o conflito e a coordenação. Dessa forma, elas são ao mesmo tempo contrangimento e libertação da ação individual, ou seja "uma concepção dinâmica da instituição, tal como a do antigo institucionalismo, que vê a instituição como regulação de conflito, e, portanto, um compromisso, mas simultaneamente como uma convenção para a cooperação, faz dela um possível ponto de convergência para os novos institucionalismos" (THÉRET, 2003, p.250).

John R. Commons, institucionalista dos arredores de 1930; uma de suas principais contribuições foi definir a transação como unidade básica de análise. 


\section{A Nova Economia Institucional - NEI}

A Nova Economia Institucional é, portanto, apenas uma das correntes da Economia Institucional e traz consigo um posicionamento teórico específico e determinante. Privilegia a atitude racional nas escolhas individuais e atribui à cooperação e à coordenação as origens das instituições, ainda que essa cooperação seja alcançada para prevenir conflitos. Isso implica dizer (vale lembrar!) que tende a excluir de sua análise atributos como cultura e conflito como determinantes nas relações.

Três correntes compõem a NEI: uma dedicada às formas de organização, com foco na firma (Coase e Williamson), mais conhecida como Economia dos Custos de Transação; outra dedicada à história econômica e às mudanças institucionais (North, Matthews), invocada em estudos sobre ambiente institucional; por fim, a corrente que se preocupa com situações de equilíbrio no contexto das interações estratégicas (Teoria dos Jogos, Schelling, Schotter, Shubik) (THÉRET, 2003, p. 232).

A NEI é apresentada por AZEVEDO (2000) em dois níveis analíticos. $\mathrm{O}$ ambiente institucional, que contempla as macroinstituições, é a base das interações entre os seres humanos ${ }^{8}$; e as estruturas de governança, que contemplam as microinstituições e regulam uma transação específica ${ }^{9}$ (AZEVEDO, 2000, p.35). No nível microinstitucional está o braço da NEI, denominado Economia dos Custos de Transação, estruturado por Williamson; e no nível macroinstitucional, o braço da NEI que se ocupa do ambiente institucional, estruturado por Douglas North.

\subsection{Economia dos Custos de Transação - ECT}

A Economia dos Custos de Transação foi desenvolvida por Williamson a partir da reflexão de Coase sobre falhas de mercado associadas a custos de transação (GUEDES, 2004) e de outras contribuições nas áreas da

Por exemplo, regras, leis e governo.

9 Por exemplo, as empresas ou firmas e os contratos. 
economia, do direito e da administração (WILLIAMSON, 1989, p 1423). Essas contribuições, segundo Williamson, confirmaram o que Coase desenvolveu em 1972 sobre o estado da análise institucional comparada ${ }^{10}$ (WILLIAMSON, 1989, p. 23).

O quadro conceitual no qual se move a Nova Economia Institucional é o neoclássico, que resgata instrumentos analíticos de Marshall (GUEDES, 2004). Três pressupostos teóricos conduzem o arcabouço analítico da NEI: a racionalidade limitada o oportunismo e a incerteza, presentes nas relações econômicas.

O trabalho de Coase, que identifica o custo de transação como variável que condiciona a formação de estruturas de governança, serviu para que Williamson melhor estruturasse a idéia de custo de transação num arcabouço teórico, considerando a firma como substituta do mercado para a relação de coordenação (WILLIAMSON, 1989. ZYLBERSTAJN; 1995; GUEDES, 2004).

Outros trabalhos, anteriores aos de 1930 e posteriores aos de 1960, foram reconhecidos por Williamson. Do resgate dessas contribuições, Williamson moldou a Economia dos Custos de Transação - ECT e a posicionou como um trabalho interdisciplinar, no qual direito, economia e administração têm papéis importantes. As contribuições nessas três áreas foram até então independentes, sem que se percebessem seus interesses comuns (WILLIAMSON, 1989, p. 13-14). Sustenta-se que as instituições capitalistas objetivaram economizar custos de transação, apesar de reconhecerem não ser este o seu único propósito. Por fim, adimitiu o enfoque microanalítico para o estudo da organização econômica (WILLIAMSON, 1989, p.13).

A partir desses resgates teóricos, Williamson definiu as 2 hipóteses comportamentais da Economia dos Custos de Transações: racionalidade limitada e oportunismo. Essas hipóteses, num ambiente complexo e imprevisível, são a razão da existência de custos nas transações. A

${ }^{10}$ Em 'The Nature Of The Firm', Coase vê a firma como um arranjo institucional que substitui a contratação transitória por um vínculo duradouro entre fatores de produção. 
dimensão desses custos depende dos atributos das transações, como freqüência, especificidade do ativo e incertezas.

Diferentes combinações de comportamento e atributos conduzem a diferentes formas de governança, que podem ser de mercado ${ }^{11}$, formas híbridas ${ }^{12}$ ou hierárquicas ${ }^{13}$. Os agentes econômicos, cientes dos custos da transação e das limitações que eles trazem ao desempenho, escolhem as estruturas de governança capazes de minimizá-los.

Essas escolhas coincidiriam com as formas de governança previstas na teoria dos custos de transação, para cada combinação de comportamento e atributos. As estruturas de governança surgem, portanto, como salvaguardas aos comportamentos oportunísticos e à racionalidade limitada. A forma de governança será formada de acordo com as combinações existentes na transação das hipóteses comportamentais e dos atributos das transações.

Destaca-se, então, um caráter preditivo na ECT, já que as formas de governança são esperadas, dadas as combinações de comportamento e de atributos. Assim, o caráter empírico do estudo dos custos de transação é menos dimensioná-los e mais "saber se as relações da organização (práticas de contratação, estruturas de governança) correspondem aos atributos das transações como prognostica o raciocínio do custo de transação" (WILLIAMSON, 1989, p. 32). Isso leva a Economia dos Custos de Transação a transitar por vetores contrários ao institucionalismo. A ECT apresenta uma teoria geral que explica a estrutura de governança, baseando-se na combinação de comportamento individual e atributos das transações. Logo, é dedutiva. O institucionalismo, por sua vez, entende que é preciso compreender as instituições particulares para explicar o caráter das transações. Nega-se, portanto, a propor uma teoria geral. Logo, é indutiva.

\footnotetext{
${ }^{11}$ Como o chamado spot, compra e venda sem vínculo duradouro. Como um carpinteiro que eventualmente seja pago para consertar uma cerca.

12 Como um contrato com um carpinteiro, que se compromete a consertar a cerca periodicamente, em datas definidas.

${ }^{13}$ Como o carpinteiro contratado como funcionário da fazenda, cuja função seja consertar a cerca sempre que necessário.
} 


\subsection{Ambiente Institucional}

O ambiente institucional é o nível analítico que compõe a nova economia institucional, caracterizado por uma análise macroinstitucional. Inclui elementos como leis, valores e aprendizado, mas não a desvincula de seu vínculo racionalista.

North, o expoente nessa análise, apontou que, em frente à incompletude de informação e à necessidade de se estabelecerem comportamentos regulares, a fim de diminuir incertezas, dada uma realidade em constante mudança e situações normalmente únicas, são desenvolvidos padrões de comportamento. Instituições, para ele, seriam esses comportamentos regulares (HIRA; HIRA, 2000).

Há alguma similaridade na definição de instituições, de Williamson e North. Para Williamson, as instituições econômicas do capitalismo são criadas e atuam com o objetivo de economizar custos de transação; para North, elas são regras criadas para diminuir incertezas, o que pode ser equivalente a diminuir custos de transação. É curioso notar que as instituições, para Williamson, são salvaguardas a comportamentos oportunísticos e à racionalidade limitada e têm o objetivo de defender as relações econômicas desses comportamentos, que, para ele, são regulares. North as vê em sentido contrário; elas criam comportamentos regulares e, por isso, diminuem incertezas, mas não está expresso que isso diminua o oportunismo ${ }^{14}$.

As instituições, em North (1993, p. 13), são, portanto, "as regras do jogo em uma sociedade ou, mais formalmente, são as limitações idealizadas pelo homem que dão forma à interação humana". Para North (1993), as mudanças institucionais revelam o modo como as sociedades evoluem e são a chave para entender a mudança histórica. Isso revela que,

\footnotetext{
${ }^{14}$ Aqui o ambiente institucional assume papel mais relevante que na Economia dos Custos de Transação sobre o comportamento dos indivíduos. Enquanto para North as instituições limitam comportamento, para Williamson elas são produto do comportamento individual.
} 
diferentemente de Williamson, aqui o indivíduo é menos autônomo, e o ambiente institucional exerce influência relevante sobre instituições.

Do arcabouço analítico, que reconhece custos de transação como variável importante à definição de eficiência econômica, decorre o reconhecimento do papel das instituições que coordenam essas transações no mercado. "Um conjunto de instituições políticas e econômicas que ofereça transações de baixo custo viabiliza a existência de mercados de produtos e fatores eficientes necessários ao crescimento econômico" (NORTH, 1994, p. 10).

O Estado, como o principal provedor das regras econômicas e da garantia de que serão cumpridas, torna-se agente crucial nessa abordagem. Ele assume uma postura autônoma, capaz portanto de moldar as preferências de maximização das organizações, e torna-se ele mesmo moldado pelo comportamento delas (HIRA; HIRA, 2000). Essa autonomia confere às instituições capacidade de afetar a distribuição de recursos, mais que simplesmente refleti-la. Elas condicionam e moldam decisões, ao fornecerem um conjunto restrito de alternativas políticas que afetam, assim, as regras das interações políticas, econômicas e contratuais.

Se forem resgatados os critérios de diferenciação entre os institucionalismos desenvolvidos, ver-se-á que North dialogou com os outros institucionalismos que atribuíam relevância à cultura e à história nas escolhas individuais.

North ampliou o conceito de instituição, ao agregar valores, crenças e cultura, ao insistir no papel das idéias, das ideologias e dos dogmas nos processos de escolha individual e ao dar mais espaço às dimensões herdadas e aos aspectos cognitivos das instituições (THÉRET, 2003, p. 242-243). Nos seus trabalhos mais recentes, questionou postulados fundamentais do institucionalismo da escolha racional, em parte, endogenizando as preferências. Isso fez com que considerasse que as instituições não apenas constrangem as escolhas, como também modelam o comportamento, além de reavaliar o papel da eficácia na seleção de instituições (THÉRET, 2003). Também colocou em perspectiva o papel 
da coerência macro-social das instituições no processo de seleção (THÉRET, 2003).

\subsection{Contribuições, limitações e contradições da Nova Economia Institucional}

O mapeamento teórico, realizado na seção 3, permite antever a natureza das limitações e contradições apontadas na Nova Economia Institucional. O vínculo dessa escola ao princípio da escolha racional e do individualismo metodológico a posiciona nos extremos dos critérios de diferenciação apresentados na seção anterior. Para a NEI, os indivíduos agem de acordo com um cálculo otimizador, e as instituições resultam de agentes que agem em cooperação, como substitutas do mercado auto-regulado. Esse posicionamento aproxima essa corrente teórica da escola neoclássica.

A falta de mediações que permitam atribuir à cultura papel relevante no comportamento dos agentes e ao conflito importância na gênese das instituições faz da NEI uma das correntes do institucionalismo mais criticadas. Essas mediações têm sido buscadas pelos expoentes da NEI, sobretudo com os recentes trabalhos de Douglas North (THÉRET, 2003), mas há quem veja nisso remendos ao princípio da escolha racional que mais o contradiz do que complementa (HIRA, HIRA; 2000).

Sucintamente, a investigação teórica permitiu identificar, como principais contribuições da Nova Economia Institucional, os seguintes aspectos:

- apresenta uma definição de custos de transação, suas causas e as consequiências para o desempenho econômico, em substituição à idéia da eficiência do mercado auto-regulado, defendido pela escola neoclássica; 
- mostra que o aumento no tamanho das organizações ${ }^{15}$ pode aumentar a eficiência pela redução do custo das transações, como os custos da incerteza entre agente e principal (HIRA, HIRA, 2000);

- explica também uma base crucial para a hierarquia em todas as instituições sociais - os benefícios da estabilidade e da previsibilidade do comportamento;

- denuncia a capacidade de organizações e de grupos de interesses em resistir às mudanças e manter o status quo (HIRA; HIRA. 2000);

- faz mediações entre a microeconomia e a macroeconomia, ao entender as instituições como mediações entre o individual e o coletivo;

- apresenta a necessidade de interdisciplinaridade na construção do embasamento teórico para a busca de eficiência e de competitividade nas estruturas de governança.

Essa abordagem interdisciplinar, proposta por Williamson, levou o assunto à área do direito, na qual já se vêem diversos e importantes trabalhos que objetivam estudar as implicações econômicas dos procedimentos e decisões jurídicas (SILVA, 2003).

Como principais limitações identificou-se que:

- do parentesco com o mainstream, a NEI herda o caráter preditivo, a partir de uma teoria geral e da constituição de modelos para a compreensão da realidade;

- ignora que instituições representam valores, rotinas, cultura (HODGSON,1998, p.172), o que atribui eficiência às estruturas de governança, embora a realidade demonstre a permanência de instituições ineficientes.

15 Referindo-se aqui à hierarquização nas empresas 
Azevedo (1996) buscou sanar parte dessa limitação, ao afirmar que poder (entendido como estratégias de apropriação) e eficiência (estratégias de custos de transação) podem atuar, conjuntamente, na formação do arranjo institucional. As proposições de Azevedo (1996) provam que, sob determinadas condições, pode-se formar um arranjo institucional ineficiente que provém do poder de barganha.

- atribui peso secundário ao ambiente institucional para a determinação de estruturas de governança (GUEDES, 2004). Daí, deduz-se que as instituições podem reduzir/aumentar os custos de transação.

A consequência disso está em separar produção e transação, conferindo a esta última autonomia em explicar as inovações organizacionais (GUEDES, 2004). No entanto, o ambiente institucional pode contribuir, quando não determinar, a especificidade dos ativos, principal fator definidor das estruturas de governança para Willamson. Isso mostra que o caráter específico dos ativos não é algo alheio ao entorno institucional. Por exemplo, algo específico em Mato Grosso do Sul, como um aparelho celular que agrega funções de cartão de crédito, não o seria em Tókio, onde esse aparelho já é popular.

Além disso, instituições externas ao mercado podem promover incentivos capazes de alterar os custos de produção e de transação. Como o ambiente institucional é dado, fica difícil compreender o efeito das inovações ou as mudanças verificadas nas instituições e firmas sobre ele (GUEDES, 2004).

- atribui eficiência às estruturas de governança (BOUVIER-PATRON, 1993), o que decorre do comportamento otimizador dos agentes. Os agentes, cientes dos custos das transações, comparam os custos sob diferentes estruturas de governança e escolhem a estrutura de menor custo, que, portanto, é mais eficiente. Assim, a eficiência é deduzida e não demonstrada;

- falha em explicar as origens e a rota das mudanças institucionais (HIRA; HIRA. 2000). Se as mudanças no ambiente institucional 
condicionam o desenvolvimento e se essas mudanças são condicionadas por fatores exógenos ao modelo (como tecnologia, cultura, ideologia e normas), então esses fatores têm importância maior para a análise.

- para North, diferenças nas instituições seriam as razões para diferenças nos resultados econômicos, sugerindo que as diferenças no desenvolvimento entre os países decorrem das instituições.

Assim, ao mesmo tempo que mantém a imagem de indivíduos autônomos, perseguindo seus interesses, inclui fatores como dependência de trajetória, valor, regras estáveis de comportamento, cultura e ideologia. Isso resolve parte das limitações da perspectiva da escolha racional, mas traz uma série de contradições.

Primeiro, North postula, por exemplo, que a violência deriva da inabilidade de instituições mediadoras, decorrentes de limitações na liberdade dos representantes políticos e na incapacidade de formar uma coalizão vencedora. Ora, se o Estado é autônomo e possui o monopólio da arbitragem, de modo a garantir o cumprimento dos contratos, essa inabilidade constitui auto-contradição, salvo se se admite que o Estado, mais que autônomo e árbitro, é jogador, no sentido de ele mesmo refletir e ser constituído por interesses (HIRA; HIRA. 2000).

Segundo, creditar às diferenças institucionais as diferenças no desenvolvimento dos países sugere crer que seria atrativo copiar, nos subdesenvolvidos, instituições vencedoras em países desenvolvidos (HIRA; HIRA. 2000). Isso requer ignorar a importância de culturas e valores na definição do ambiente institucional, algo caro à estrutura teórica de North. Também ignora os condicionantes históricos do subdesenvolvimento, provenientes dos próprios relacionamentos comerciais entre países de diferentes desenvolvimentos. A nãomimetização das instituições por países de baixo desenvolvimento é explicada pela "dependência de trajetória", mas a explicação disso não é satisfatória. As fraquezas organizacionais e institucionais podem advir 
também, além da trajetória, de uma variedade de pressões naturais e externas, como inundações e variação nos preços das commodities (HIRA; HIRA. 2000).

Terceiro, as mudanças, que para North condicionam o crescimento, ocorrem a despeito das instituições e dos incentivos que elas supostamente sugerem, ou das resistências e das experiências dos agentes internos ou empresários. Elas podem vir de grupos de fora do sistema, via manifestações, lobby ou resistência, e de choques exógenos provenientes de crises econômicas. Exemplos são a queda do bloco oriental na Europa e a liberalização de economias do terceiro mundo, a despeito das perdas que provocam para os agentes econômicos internos (HIRA; HIRA, 2000).

A ação empreendedora de agentes privados como fonte de mudança e o Estado cristalizado na cultura também parecem inadequados. $\mathrm{O}$ desenvolvimento conduzido pelo Estado na Ásia, EUA e Europa, bem como a estagnação provocada por ele na América Latina e África, sugere que as fontes de mudança diferem de sociedade para sociedade e de situação para situação (HIRA; HIRA. 2000).

O conceito dado a instituições, entendidas como as "regras do jogo que limitam a ação humana", ofusca e subestima a importância do poder, posição e prestígio na manipulação ou simplesmente no ato de ignorar essas regras; também subestima a importância da personalidade. Pessoas como Pinochet, Getúlio Vargas, Stalin e Park, na Coréia do Sul, podem fazer a diferença nos resultados econômicos e na condução de mudanças nas regras (HIRA; HIRA. 2000).

North, como visto, afirma que as mudanças são gradativas, dada a resistência de instituições, especialmente as informais, mas o crescimento excepcional no leste asiático parece contradizer esse gradualismo. 


\section{Implicações no estudo do agronegócio brasileiro}

Viu-se que as atividades agropecuárias, entendidas como um nexo de contratos, são a base da abordagem de Sistemas Agroindustriais (ou Commodity Sistem Approach). Essa abordagem remete a uma visão sistêmica do agronegócio, cujo conceito de competitividade de eficiência passa pela capacidade do sistema em adaptar-se ao ambiente econômico e a suas mudanças. Com isso, a transação entre os elos do sistema passa a ser uma unidade relevante de análise. Os contratos, os agentes coordenadores e, portanto, as instituições assumem papel relevante na condução do crescimento e do desenvolvimento do sistema. Isso remeteu os estudos sobre o agronegócio ao enfoque institucionalista, no qual as instituições, mais que os preços, funcionam como reguladoras das transações no mercado.

O braço institucionalista com maior parentesco ao enfoque de Commodity Sistem Approach, ou Sistema Agroindustrial-SAG, é a Nova Economia Institucional, por privilegiar a transação como unidade básica de análise e, portanto, dar especial importância aos contratos e à forma de coordenação do sistema. Daí, sua aplicação nos estudos sobre agronegócios. No entanto, isso tem trazido implicações negativas na compreensão do agronegócio brasileiro, visto que essa realidade tem apresentado elementos não condizentes com os pressupostos da Nova Economia Institucional.

Essa visão que a NEI proporciona obscurece a importância dos conflitos dentro do sistema, seja por diferenças no poder de barganha entre os agentes, que privilegia os ganhos em prol dos maiores em detrimento dos menores, seja por questões culturais ou históricas. Apesar disso, nem os conceitos teóricos da NEI nem a concepção do SAG permitem ampliar o campo de análise para além das escolhas racionais, incluindo, aí, conflito, história e cultura, sem que choque com seus pressupostos teóricos.

Essa seção objetivou investigar estudos empíricos sobre agronegócios calcados na NEI, procurando observar como a teoria é escolhida e de 
que forma apresenta ou oculta o debate teórico apresentado. Trata-se de buscar compreender a clareza com que o posicionamento teórico é revelado; em seguida, investigar como esse posicionamento teórico conduz à compreensão do objeto estudado.

O primeiro artigo a ser analisado trata dos custos de transação na distribuição de tomate, a partir dos conceitos da Economia dos Custos de Transação (LORENZANI, 2004); o segundo faz um estudo da avicultura a partir da abordagem da NEI (ZIEBERT; SHIKIDA. 2004); e o terceiro avalia as cadeias produtivas do açúcar ao estado de São Paulo e da França (AMARAL, et alli, 2003), fazendo uma análise comparativa. A tarefa deste trabalho é buscar o que está teoricamente implícito nessas análises.

\subsection{ECT e distribuição de tomate in natura}

Lorezani e Silva (2004) fizeram um estudo dos custos de transação na distribuição de tomate in natura a partir da Economia dos Custos de Transação. Os resultados alcançados mostram que, de fato, houve maior eficiência na distribuição de tomate in natura, mas isso foi acompanhado por aumento na rivalidade entre os agentes da cadeia.

Essa autora observou que o comportamento cooperativo entre agentes da cadeia, com o objetivo de diminuir custos de transação, como supõe a ECT, não ocorre em alguns canais do setor de frutas, legumes e verduras, "ao contrário, são observados comportamentos adversais entre os agentes envolvidos" (LORENZANI, 2004, p. 2). Isso, no entanto, parece não oferecer à autora elementos que a desobriguem de permanecer vinculada à ECT. Ao contrário, por conta disso, a coordenação da cadeia é vista como um "desafio" a ser alcançado (LORENZANI, 2004, p. 2).

A utilização da ECT é justificada por três razões: primeiramente, porque está presente no agronegócio uma série de arranjos organizacionais, que passam desde o mercado spot a arranjos hierarquizados, ou integração 
vertical; segundo, a forte interação entre organizações desse setor e as instituições, notadamente pelas intervenções do Estado; por fim, a incerteza presente na atividade agroindustrial.

Ora, parece que a teoria escolheu suas razões, não as razões, a teoria, ou seja, são razões que, a rigor, poderiam invocar qualquer outra corrente do institucionalismo, salvo se o que se entende por institucionalismo seja sinônimo de Nova Economia Institucional.

De fato, como visto, a ECT oferece elementos para a análise de diferentes estruturas de governança, uma de suas contribuições. Seu foco microinstitucional permite a análise de interações específicas, no entanto, seu quadro conceitual não responde à complexidade observada pela autora na distribuição de tomate in natura. Os arranjos organizacionais, ou as estruturas de governança adotadas no setor, como o estudo detectou, são consequiências do poder de mercado exercido por grandes varejistas, não da cooperação em prol de um melhor desempenho sistêmico, como sugere a estrutura teórica da ECT casada ao enfoque de sistema agroindustrial.

As estruturas encontradas na distribuição de tomate in natura intensificam rivalidades e são instrumentos de imposição de atitude oportunista por parte de quem detém maior poder de barganha. Isso não passou despercebido pelas autoras, que observaram que, "freqüentemente, os contratos feitos entre fornecedores e centrais de compras das grandes redes de auto-serviços beneficiam as duas partes de forma bastante desigual, devido ao poder de barganha exercido pelas redes." (LORENZANI; SILVA, 2004, p. 8)

\subsection{NEI e produção avícola cooperada}

Ziebert e Shikida (2004), ao analisarem o modelo de produção integrada na avicultura, por meio de cooperativa em Santa Helena (PR), à luz da NEI, observaram que a produção integrada é vista pelos integrados como 
um mecanismo que atenua incertezas. No entanto, sob a ótica da cooperativa, grande empresa sob a qual se integraram os produtores, os contratos são vistos como garantidor de prazos e produtos.

A relação entre produtores e cooperativa se dá a partir do planejamento produtivo da empresa. Segundo esses autores, ela fornece aos produtores os pintinhos, rações, vacinas e translado entre fazenda e indústria. Aos produtores, cabe fornecer mão-de-obra e instalações. A empresa paga aos produtores e desconta os materiais cedidos para a criação dos frangos.

A firma vista de forma não convencional, tratada como um complexo de contratos que governam as relações internas e externas, serve de justificativa para a aplicação da NEI. Novamente, aqui, qualquer corrente do institucionalismo poderia ser invocada por essas mesmas razões, mas o autor sustenta que a abordagem microinstitucional, fornecida pela NEI, permitiria melhor compreensão do objeto focado, ou seja, a transação entre produtores e empresa.

A objetividade que a NEI fornece para a compreensão de relações específicas e microinstitucional acaba sendo invocada para os estudos empíricos. Essa objetividade fornece alguma clareza das transações, traz consigo os vícios de seu alinhamento teórico, ou seja, o vínculo ao individualismo metodológico e às escolhas racionais, que obscurece questões relevantes para o estudo das cadeias produtivas brasileiras, como história, cultura e valores morais, e tende a enxergar as relações como produto de atitudes cooperativas. Não é a toa que os autores observaram que os contratos devem ser elaborados para produzir cooperação entre os agentes envolvidos (ZIEBERT E SHIKIDA, 2004, p. 78).

Os resultados empíricos mostram que integrados e empresa estão satisfeitos com o contrato, mas isso não inibe o poder de mercado que a empresa exerce sobre os integrados, estabelecendo uma relação monopólio-monopsônio, em que somente a empresa pode vender os insumos aos integrados e somente ela comprar deles o produto final. Apesar disso ser visto negativamente pelos integrados, o contrato 
cooperativo atenua incertezas e riscos que eles não estariam dispostos a assumir.

A NEI mostrou-se suficiente para o estudo em questão, embora o objeto estudado já traga consigo parte dos pressupostos da NEI, que é a ação cooperativa. Assim, a realidade não se choca com a teoria e ela, nesse caso, de fato consegue revelar questões importantes das transações. O que não aborda (conflito, cultura) seria apenas complementar, e sua falta não produz deficiências relevantes ao estudo.

\subsection{NEI e cadeias produtivas do açúcar}

Amaral, Neves e Moraes (2003), ao fazerem um estudo comparativo entre cadeias produtivas do açúcar de São Paulo e da França, à luz da Economia dos Custos de Transação, Teoria da Organização Industrial e o Sistema Agroindustrial, focaram especificamente nos elos produtor de matéria-prima e de processamento industrial.

O foco na transação, novamente, é razão para a escolha da ECT. Como já dito, de fato, isso constitui contribuição relevante da ECT no mundo institucionalista. Ela traz consigo, no entanto, os paradigmas da estrutura eficiente e da coordenação, como aplicável a qualquer realidade analisada. Afirmaram os autores, inspirados pela teoria, que diante de um processo de escolha entre diferentes arranjos organizacionais, predomina a que é mais eficiente, ou seja, a que minimiza os custos de transação. Em seguida, "a tentativa de minimização dos custos explica os diferentes arranjos organizacionais na cadeia" (AMARAL; NEVES; MORAES, 2003, p.68). Não houve nenhuma referência a poder, cultura ou conflito. O instrumento teórico, assim absolutizado, absolutiza também o olhar sobre o objeto estudado.

Esses autores observaram que há maior poder de barganha no elo industrial, mas que os pequenos produtores, se agrupados em cooperativas e associações, teriam condições de obter maior poder de barganha e 
obterem maiores vantagens. "Nesse sentido, a participação em cooperativas e associações de fornecedores torna-se forma importante de redução de assimetria de informação, bem como facilita a coordenação para negociações conjuntas" (AMARAL; NEVES; MORAES, 2003, p $70)$.

Ora, se é verdade que a forma organizacional resultante é a mais eficiente, restaria saber a razão pela qual os pequenos produtores de açúcar já não se organizaram em cooperativas. Talvez, porque haja mais fatores que influenciam a escolha da forma organizacional do que as supostas pela ECT, mas essa é uma hipótese não levantada no estudo.

Na discussão teórica desenvolvida na seção 4, observou-se que uma das críticas à ECT é que a eficiência da forma organizacional é deduzida e não demonstrada, conforme observado no estudo empírico. A cadeia do açúcar teve, desde 1930, forte intervenção estatal, deixando de tê-la a partir de 1999/2000, quando oferta e demanda passaram a interferir na formação de preços. Quando da intervenção, o Estado conduzia os programas, de modo a induzir à hierarquização da produção, e fazia com que as usinas, além de atuarem no processamento, atuassem também na produção da matéria-prima. O estudo empírico, ao observar que pós2000 a hierarquização permaneceu, deduz que essa é, portanto, a forma organizacional mais eficiente na produção do açúcar brasileiro, pois, ao ter oportunidade de relacionar-se no mercado, a cadeia não o fez.

O estudo assim apresentado não exclui outras hipóteses, como o poder de grupos de usineiros sobre o Estado, o poder de mercado obtido nos anos de proteção estatal, ou mesmo a idéia de que a forma hierarquizada seja resultado da própria construção histórica, que, ao privilegiar nos anos de proteção a produção hierarquizada, teria impossibilitado a formação de grupos de produtores menos capacitados para atuarem no mercado e, mesmo organizados em associações, como sugerem os autores no início do trabalho, conquistado poder de barganha junto às usinas. $\mathrm{O}$ Estado aparece alheio ao poder político. 
A eficiência, assim deduzida, empobrece os estudos sobre o agronegócio brasileiro, que tem histórica e culturalmente relações profundas com a formação econômica do Brasil. A classe sucroalcooleira e sua origem latifundiária exerceram poder sobre o Estado, que não atuaram, em muitos momentos, de forma distanciada, como se objetivasse o bom desempenho sistêmico.

\section{Considerações finais}

Este trabalho permitiu compreender que a Nova Economia Institucional se associa a uma linha de pensamento que privilegia o racionalismo nas relações e compreende o indivíduo como autônomo em suas decisões. As instituições seriam resultado dessa ação do indivíduo, que age cooperativamente ou coordenadamente, e serviriam como instrumento para atenuar custos provenientes da racionalidade limitada do indivíduo. Como o indivíduo é motivado por seus interesses e age de forma a satisfazê-los (ou seja, age racionalmente), as instituições seriam eficientes.

O institucionalismo original, ou o 'velho institucionalismo', associa-se a uma linha de pensamento que atribui importância à formação sociológica, histórica e cultural nas escolhas do indivíduo. O indivíduo, assim compreendido, é menos autônomo ou menos calculador, e suas decisões são motivadas por questões morais e culturais, hábitos e rotinas. As instituições são compreendidas de forma mais ampla e podem resultar em ineficiência, do ponto de vista econômico. Os indivíduos nascem num mundo de instituições, e suas escolhas estão condicionadas por elas.

A Nova Economia Institucional induz a tomar o ambiente institucional como dado e, portanto, inerte sobre o comportamento individual, ou seja, o comportamento individual não é influenciado pelo ambiente institucional, o que limita o campo de análise da NEI a relações específicas. No entanto, ela se apresenta como uma teoria geral para análise das relações capitalistas. 
Douglas North, ao incluir no campo de análise da NEI o ambiente institucional, composto de regras formais (leis, normas, etc.) e regras informais (moral, cultura, hábitos), tenta superar essa limitação, mas o vínculo ao individualismo metodológico torna contraditória a inclusão dessas variáveis na condução das relações econômicas. Isso pressupõe ter de admitir que as instituições podem resultar em ineficiência. Se resultarem em ineficiência, todo o arcabouço da ECT tornar-se-á questionável.

A NEI dificulta observar a contradição implícita da teoria quando a realidade agroindustrial apresenta formações organizacionais ineficientes, ou mesmo eficientes, propulsoras de rivalidades (como no caso da distribuição do tomate in natura). A coordenação da cadeia é apontada como uma política capaz de gerar eficiência sistêmica, ainda que a realidade tenha apontado impedimentos para tal coordenação.

Já nas relações cooperativas (como no caso da avicultura integrada), a NEI não se choca com a realidade, pois elas se comportam de acordo com os pressupostos da NEI. Está implícita nesses casos, como é implícita na NEI, a ação coordenada entre os agentes.

Assim, este estudo mostra que a NEI deve ser usada com cautela, procurando observar o que ela não explica, mas que pode estar presente no objeto estudado, como as estruturas ineficientes e a resistência de agentes econômicos em promover a tão recomendada coordenação sistêmica. Nada exclui a hipótese de essas "anomalias", do ponto de vista da NEI, serem fruto de variáveis históricas e culturais. No entanto, ao incluir essas variáveis, o estudioso precisa estar atento às contradições da NEI que elas evidenciam.

A análise microinstitucional não pode prescindir da análise histórica e sociológica, pois estão presentes nas transações específicas os condicionantes resultantes dessas dimensões. 


\section{Referências}

AMARAL, Taís Mahalem do; NEVES, Marcos Fava; MORAES, Márcia A. Dias de. Cadeias produtivas do açúcar do estado de São Paulo e da França: comparação dos sistemas produtivos, organização, estratégias e ambiente institucional. Agric. São Paulo, SP, 50(2):6580, 2003. Disponível em www.periodicos.capes.br. Acesso em 09/09/ 07.

AZEVEDO, Paulo Furquim. Nova Economia Institucional: referencial geral e aplicações para a agricultura. Agric. São Paulo, SP, 47 (1): 33-52, 2000 .

AZEVEDO, Paulo Furquim. Integração vertical e barganha. São Paulo: tese de doutorado. Faculdade de Economia, Administração e Contabilidade. Departamento de Economia. Universidade de São Paulo. 1996.

BLISKA, Flávia Maria de Mello; GUILHOTO, Joaguim José Martins. Relações entre as exportações brasileiras de carnes e a economia brasileira. Agric. São Paulo, SP, 47(1):1-31, 2000. Disponível em: www.periodicos.capes.br. Acesso em: 09/09/07.

BATAlHA, Mário Otávio; SILVA, Carlos Arthur B. da. (Coords.) A eficiência econômica e competitiva da cadeia agroindustrial da pecuária de corte no Brasil. Brasília: CNI/IEL/CNA/SEBRAE, 1999.

CASTRO, Ana Célia. Construindo Pontes: Inovações, Organizações e Estratégias como Abordagens Complementares. Revista Brasileira de Inovação. Volume 3, Número 2, julho/dezembro 2004. p. 449-474.

CONCEIÇÃO, Octavio. Os institucionalistas e a constituição de uma teoria econômica das instituições. In: V ENCONTRO DE ECONOMISTAS DA LÍNGUA PORTUGUESA, 5 - 7 de novembro de 2003. Recife. Disponível em: www.race.nuca.ie.ufrj.br. Acessado em: 05/09/2004 
DIMAGGIO, P. e POWELL, W. (1997). Le néo-institutionnalisme dans l'analyse des organisations, in Politix, n. 40, 1997.

FARINA, Elizabeth M M Q; ZYLBERSZTAJN, Décio. Competitividade e organização das cadeias agroindustriais. In: ZYLBERSZTAJN, D.; GIORDANO, S. R.; GONÇALVES, M. L. Fundamentos do Agribusiness - I Curso de Especialização em Agribusiness. UFPb/PEASA/USP/PENSA. Campina Grande, Pb, 1996.

FARINA, E. M. M. Q.; AZEVEDO, P. F.; SAES, M. S. M. Competitividade: mercado, estado e organizações. São Paulo: Editora Singular/Fapesp/Pensa, 1997.

FIANI, Ronaldo. Teoria dos Custos de Transação. In KUPFER, D.; HASENCLEVER, L. Economia Industrial: fundamentos teóricos e práticas no Brasil. Rio de Janeiro: Campus, 2002.

GASQUES, J. G. et al. Desempenho e crescimento do agronegócio no Brasil. Brasília: IPEA, 2004. Texto para discussão n. 1009. Disponível em: http://ipea.gov.br Acessado em: 14/05/2004.

GRUCHY, A. G. Three Different Approaches to Institucional Economics: An Evaluation, Journal of Economic Issues, vol. XXIV, ${ }^{\circ}$. 2, june, 1990.

GOLDBAUM, S. A teoria dos custos de transação é funcionalista? In: Anais do Primeiro Seminário Brasileiro da Nova Economia Institucional. São Paulo. 5-7/Agosto/1998. 15p

GUEDES, Sebastião Neto Ribeiro. Observações sobre a economia Institucional: há possibilidade de convergência entre o velho e o novo institucionalismo? Disponível em: www.race.nuca.ie.ufrj.br. Acesso em: 05/09/2007. 
HALL, Peter A. e TAYLOR, Rosemary C. R. As três versões do neo-institucionalismo. Lua Nova. [online]. 2003, no.58 [citado 07 Outubro 2004], p.193-223. Disponível: <http://www.scielo.br/ s c i e lo.ph p ? s c ri p t $=\mathrm{s} \mathrm{ci}_{-}$a r t t e x t \& pi d = S 0102 $64452003000100010 \& \operatorname{lng}=\mathrm{pt} \& n \mathrm{~mm}=\mathrm{iso}>$. ISSN 0102-6445.

HIRA, Anil; HIRA, Ron. The new institutionalism: contradictory notions of change. American Jornal of Economics and Sociology, v.59, n. 2, p 267-282, april, 2000.

HODGSON, G. The approach of institutional economics. Journal of Economic Literature. Vol 36, 1998. 166-192p

JANK, Marcos Sawaya. Competitividade do agribusiness brasileiro: discussão teórica e evidências no sistema carnes. São Paulo, 1996. Tese (Doutorado) - FEA-USP.

LOURENZANI, Ana Elisa Bressan; SILVA, Andréa Lago da. Custos de transação na distribuição de tomate in natura. Agric. São Paulo, São Paulo, v. 51, n. 1, p. 41-50, jan./jun. 2004. Disponível em www.periodicos.capes.br. Acesso em 09/09/2004.

MENDONÇA, Alex. A Empresa e o Meio Ambiente: As Escolas Neoclássica, Institucionalista e Evolucionista. In: V ENCONTRO DE ECONOMISTAS DE LÍNGUA PORTUGUESA, 5 - 7 de novembro de 2003. Recife. Disponível em: www.race.nuca.ie.ufrj.br. Acesso em: 05/ $09 / 2004$

NEVES, Marcos Fava; SCARE, Roberto Fava; CAVALCANTI, Miguel de Rocha. Comercialização internacional de produtos animais provenientes de pastagens. Beefpoint, 2003. Disponível em: http:// www.beefpoint.com.br/bn/utils/ print.asp?id artigo $=6705 \& n v=1$. Acessado em: 19/03/2007.

NORTH, D. C. Instituciones, cambio institucional e desempenho econômico. Parte I: Introducción a las instituciones e al cambio 
institucional pp 13-22. Ed. Fondo de Cultura Econômica. México, 1993 NORTH, Douglass. Custos de Transação, instituições e desenvolvimento econômico. Rio de Janeiro: Instituto Liberal, 1994.

PONDÉ, J.L.S. Coordenação e aprendizado: elementos para uma teoria das inovações institucionais nas firmas e nos mercados. Campinas, 1993. 152p. Dissertação (Mestrado) - Instituto de Economia, Universidade de Campinas.

SILVA, Germán Burgos. Estado de Derecho y desarrollo económico: aportes y limitaciones de los análisis neoinstitucionales. Chile: IIGOV, 2004. Disponível em: http://www.iigov.org/revista/?p=12_08. Acesso em: 09/09/2004.

THERET, Bruno. As instituições entre as estruturas e as ações. Lua Nova. [online]. 2003, no.58 [citado 07 Outubro 2004], p.225-254. Disponível: <http://www.scielo.br/ scielo.php?script $=$ sci_arttext\&pid=S0102-64452003000100011 \&lng=pt\&nrm=iso $>$. ISSN 0102-6445.

WILliAMSON, John. Depois do Consenso de Washington: uma agenda para reforma econômica na América Latina. Conferência. São Paulo: Semana do Economista, FAAP, 2003. Disponível em: . Acesso em: $11 / 11 / 2004$

WILLIAMSON, O. E. Las instituciones económicas del capitalismo. Ed. Fondo de Cultura Económica. México, 1989, pp. 1352.

. Comparative economic organization: the analysis of discrete structural alternatives. Administrative Science Quarterly, v.36, p.269-96, Jun. 1991.

ZIEBERT, Roger André; SHIKIDA, Pery Francisco Assis. Avicultura e produção integrada em Santa Helena, estado do Paraná: uma 
abordagem a partir da nova economia institucional. Agric. São Paulo, São Paulo, v. 51, n. 1, p. 71-86, jan./jun. 2004. Disponível em www.periodicos.capes.br. Acesso em 09/09/04.

ZYLBERSTAJN, D. Estruturas de governança e coordenação do agribusness: uma aplicação da Nova Economia das Instituições. São Paulo, 1995. Tese (Livre- Docência). FEA-USP.

ZYLBERSZTAJN, D. Conceitos gerais, evolução e apresentação do sistema agroindustrial. In: ; NEVES, M. F. (Orgs.) Economia e gestão de negócios agroalimentares. São Paulo: Pioneira Thomson Learning, 2000.

\begin{abstract}
This paper presents the theoretical roots from which emerges the New Institutional Economics (NIS). It shows that the NIS, in discussion with other branches institutionalists, reveals important theoretical limitations and contradictions. The lack of that rescue in studies on agribusiness prevents the observation of important issues of the Brazilian agribusiness, such as conflict, power and culture in the formation of structures of governance. The paper presents, first, the link between the understanding agribusiness in its systemic form and the institutionalist thought. Then, recovers the sources and branches of Institutional Economics, and shows that NIS is linked to the methodological individualism, which differs from the original institutionalism. It is concluded that the NIS is limited theoretical framework to understand the structures of governance observed in Brazil, mainly in the Brazilian agribusiness.
\end{abstract}

Keywords: Institutionalism, New Institutional Economics, supply chains. 